\title{
MODELLING AND SIMULATION OF SURFACE ROUGHNESS IN FACE MILLING
}

\author{
Simunovic, G.; Simunovic, K. \& Saric, T. \\ University of Osijek, Mechanical Engineering Faculty in Slavonski Brod, Trg I. Brlic Mazuranic 2, \\ HR 35000 Slavonski Brod, Croatia \\ E-Mail: goran.simunovic@sfsb.hr
}

\begin{abstract}
The paper presents a research on machined surface roughness in face milling of aluminium alloy on a low power cutting machine. Based on the results of the central-composite plan of experiment with varying machining parameters (number of revolutions - spindle speed $n$, feed rate $f$ and depth of cut $a$ ) and the roughness observed as output variable, two models have been developed: a regression model and a model based on the application of neural networks (NN model). The regression model (coefficient of determination of 0.965 or 0.952 adjusted) with insignificant lack of fit, provides a very good fit and can be used to predict roughness throughout the region of experimentation. Likewise, the model based on the application of neural networks approximates well the experimental results with the level of RMS (Root Mean Square) error in the phase of validation of $4.01 \%$.

(Received in February 2012, accepted in March 2013. This paper was with the authors 4 months for 2 revisions.)
\end{abstract}

Key Words: Face Milling, Central Composite Design, Regression, Neural Networks, Modelling and Simulation

\section{INTRODUCTION}

Surface quality of machined parts is often one of the most specified customer requirements and essential exploitation request where major significant indicator of surface quality is surface roughness. The surface roughness is affected by many controlled process parameters (including cutting speed, depth of cut and feed rate) and uncontrolled process parameters (cutting conditions, material properties of tool and workpiece, workpiece quality, tool geometry, tool machine vibrations, tool wear etc.) that are difficult to achieve and continuously monitor [1-7]. Surface quality, respectively surface roughness, has an important influence on technological time and costs, i. e. productivity [8]. On this basis, many scientificresearch projects and scientific papers of experimental investigations which are largely based on previously conducted and planned experiments aim at optimizing cutting parameters, modelling and predicting surface roughness to obtain a desired level of surface quality of machined products [9]. In this sense, many statistical (regression) models and models based on the application of artificial intelligence models have been developed.

In paper [10] two modelling approaches, regression and Artificial Neural Network (ANN) are applied to predict minimum surface roughness in the end milling machining process. Both models predicted 1-1.5\% lower values of roughness with regard to experimental values. In paper [11] the authors apply the same methods, and considering the input parameters of cutting speed, feed rate and depth of cut neural networks achieved better prediction of surface roughness. After the previously conducted Taguchi plan of experiment, in paper [12] the authors developed different types of neural networks (radial base, feed forward and generalized regression) which evaluated surface roughness after face milling of Al alloy 7075-T7351 based on input values (cutting speed, feed per tooth, axial depth of cut, chip's 
width, and chip's thickness). The best results were achieved by the feed forward neural network. The investigation also showed that the surface roughness was most affected by the chip thickness and cutting speed. Paper [13] deals with the surface roughness modelling in accordance with the conducted full factorial design of experiments in end milling of AISI 1040 steel material with TiAlN solid carbide tools under wet conditions. ANN based on Back-propagation learning algorithm is used to develop the surface roughness model. With the support of $\mathrm{NN}$ and the application of genetic algorithms (GA) the optimization of the machining regime was performed resulting in the roughness reduction by nearly $12 \%$, the machining time by about $20 \%$, and the roughness prediction model proved applicable with an error of about $3 \%$.

In papers [14-16] the authors model the surface roughness in end-milling of 6061 aluminium. The authors in paper [14] carry out the machining with high speed steel (HSS) and carbide tools under dry and wet conditions and they have developed a mathematical model using response surface methodology integrated with GAs. In paper [15] the authors apply adaptive neuro-fuzzy inference system (ANFIS) and GA. The model input variables are the spindle speed, feed rate, depth of cut and the workpiece-tool vibration amplitude. The ANFIS with GAs are trained with a subset of experimental data. The obtained model is tested using the set of validation data (obtained by experiment). The results show improvement in comparison with the other soft computing techniques like genetic programming (GP) and ANN. The authors in [16] model surface roughness by the application of multivariate regression analysis (MRA), ANN and ANFIS. The model input variables are the same as in paper [15]. The results of all three methods are satisfactory but the test performance of ANFIS is better than ANN and MRA. In paper [17] the authors analyse the influence of cutting speed, feed, and depth of cut on surface roughness in face milling process. For roughness modelling, based on the data collected by the planned experiment, they apply three methodologies: regression analysis, support vector machines and Bayesian neural network (BNN). All three models have the relative prediction error below $8 \%$. The BNN shows the best prediction of surface roughness with the average relative prediction error of $6.1 \%$. Feed exerts the strongest influence on roughness. The authors in paper [18] propose the application of two different hybrid intelligent techniques, ANFIS and radial basis function neural network- fuzzy logic (RBFNN-FL) for the prediction of surface roughness in end milling. In addition to speed, feed, depth of cut, which are frequently used as the model input parameters, the vibrations occurring during machining are also considered. Both hybrid techniques proved quicker and more accurate with regard to the application of individual techniques. An inprocess surface roughness adaptive control system in end milling operations was researched and developed in the paper [19]. The authors developed two subsystems: the multipleregression-based in-process surface roughness evaluation (ISRE) subsystem for predicted surface roughness during the finish cutting and the in-process adaptive parameter control subsystem. As variables these systems use machine cutting parameters such as feed rate, spindle speed, and depth of cut, and cutting force signals detected by a dynamometer sensor ISRE subsystem predicted surface with an accuracy of $91.5 \%$.

Modelling of surface roughness and waviness (surface texture) by the application of regression analysis for various cutting conditions after face-milling is dealt with in paper [20]. The roughness of face-milled surfaces is also influenced by tool service time. The authors in [21] have developed a regression model showing that roughness is a quadratic function of tool service time. The authors [22] present a technique developed using hybridization of kernel principal component analysis based nonlinear regression and GAs to predict the optimum values of the radial rake angle, speed and feed rate in end milling machining process so that the estimated surface roughness is as low as possible. The proposed technique gives a more accurate prediction model than the one obtained by the ordinary linear regression approach. 
Compared with the experiment data and RSM, the described technique reduces the minimum surface roughness by about $45.3 \%$ and $54.2 \%$. El-Sonbaty et al. [23] predicted a surface roughness using a feed forward back propagation neural network with different structures. Input variables are: spindle speed, feed, depth of cut, and pre-tool wear vibration level. There are two output variables: fractal dimension parameters and vertical scaling parameter, which characterize the machined surface profile. The best structure predicts the roughness profile with an accuracy of $98 \%$. Zain et al. [24] presented ANN for surface roughness prediction using two level full factorial designs. The authors concluded that minimum surface roughness can be obtained with high cutting speed, low feed rate, and rake angle. The paper [25] presents a new approach to determine the optimal cutting parameters leading to the minimum surface roughness in face milling of X20Cr13 stainless steel, by integrating ANN and harmony search algorithm (HS). Palani and Natarajan [26] developed a noncontact machine vision system integrated with an ANN for surface roughness prediction of end-milled parts. A self-organized map neural network uses five input variables: cutting speed, feed rate, depth of cut, and particular characteristics of the photograph, while surface roughness is the output variable. This system's advantage is the surface roughness prediction in real time and its accuracy of prediction is $97.53 \%$. Authors in [27] emphasize the importance of ergonomics in tooling operations. Bruni et al. [28] use feed forward ANN and multiple regression models for surface roughness prediction and tool wear control in AISI 420B stainless steel end milling under various cutting conditions: dry, wet, and minimum lubricant quantity-MQL. The MQL cutting results in the lowest surface roughness and the least tool wear, at high speed cutting in particular.

The investigation presented in this paper is aimed at the machined surface roughness modelling in end milling of aluminium alloy on a low power milling machine. Investigations on such machines are not common and the cutting quality greatly depends on the technologist's and the machine operator's experience.

\section{EXPERIMENTAL}

The material of the specimens is the aluminum alloy $\mathrm{Al} 6061$ (AlMg1 SiCu); the chemical composition is given in Table I. The tested samples of $70 \times 30 \times 30 \mathrm{~mm}$ were previously cut from the sheet on a cutting machine with cooling to ensure the structure and properties of material unchanged. Experimental machining was performed on a vertical CNC milling machine, type PC Mill 105 using a high speed steel milling cutter of diameter $40 \mathrm{~mm}$, HSS MAYESTAG $\varnothing 40 \times 32 \times 16$ N3074-Q45 (commercial name) with 6 cutting edges. The tool was preset and measured before use on a measuring machine so that all the cutting edges were of the same height.

The output variable i.e. surface roughness $R_{a}$, was measured using a device Talysurf Surtronic duo. This is a contact diamond stylus profiler. For this kind of device, a diamond stylus is moved across the peaks and valleys of the surface to be measured. During the measurement, room temperature was $20^{\circ} \mathrm{C}$.

Table I: Chemical composition of aluminum alloy.

\begin{tabular}{|cccccccccc|}
\hline Element & $\mathrm{Al}$ & $\mathrm{Cr}$ & $\mathrm{Cu}$ & $\mathrm{Fe}$ & $\mathrm{Mg}$ & $\mathrm{Mn}$ & $\mathrm{Si}$ & $\mathrm{Ti}$ & $\mathrm{Zn}$ \\
\hline \hline $\mathrm{wt}, \%$ & 97.4 & 0.3 & 0.2 & 0.1 & 1.0 & 0.1 & 0.6 & 0.1 & 0.2 \\
\hline
\end{tabular}

Prior to the main experiment, two pre-experiments were conducted to try the experimental and measurement technique, as well as to define the levels of three quantitative factors. It was concluded that three factors will be varied over the following ranges: 
- depth of cut - from 0.3 to $0.8 \mathrm{~mm}$,

- feed rate - from 50 to $100 \mathrm{~mm} / \mathrm{min}$,

- number of revolutions (spindle speed) - from 500 to $1000 \mathrm{rev} / \mathrm{min}$.

The next step was to choose the experimental design. The central composite design (CCD) was chosen. These designs are often used for fitting the second-order model (with quadratic term) in the frame of Response surface methodology, but they can be used independently too. It consists of $2^{k}$ factorial ( $k$ - number of factors) with $n_{f}=2^{k}$ number of factorial runs, $2 k$ axial runs and $n_{c}$ center runs. For this study, the number of factors $k$ is 3 , so the number of factorial runs $n_{f}$ is 8 , the number of replications in the center is 6 , and there are 6 axial runs. Therefore, the total number of runs is 20 . The parameter $\alpha$, the position of the axial runs from the center of experiment is 1.68179 (according to the $n_{f}^{1 / 4}$ ) [29], and this design is called rotatable CCD.

Table II presents five levels of three factors $A, B$ and $C$ (factor $A$ : depth of cut $a$, factor $B$ : feed rate $f$ and factor $C$ : number of revolutions $n$ ).

The experiment is performed taking into account the basic principles of experimental design (randomization and replication). For the investigation in this paper, the third principle, blocking was not used because the machining of the specimens was conducted on a single machine, it was the same operator, measuring the response was carried out by one person, the experiment was performed on the same day and the material of specimens was taken from the same batch.

Table II: The levels of the factors.

\begin{tabular}{|c|l|c|c|c|c|c|}
\hline \multirow{2}{*}{ Factor } & \multirow{2}{*}{ Units } & \multicolumn{5}{|c|}{ Levels - coded and actual } \\
\cline { 3 - 7 } & & -1.68179 & -1 & 0 & +1 & +1.68179 \\
\hline$A(a)$ & $\mathrm{mm}$ & 0.13 & 0.30 & 0.55 & 0.80 & 0.97 \\
\hline$B(f)$ & $\mathrm{mm} / \mathrm{min}$ & 32.96 & 50.00 & 75.00 & 100.00 & 117.04 \\
\hline$C(n)$ & $\mathrm{rev} / \mathrm{min}$ & 329.55 & 500.00 & 750.00 & 1000.00 & 1170.45 \\
\hline
\end{tabular}

\section{REGRESSION MODELLING}

Table III shows the results of the experiment (the last column presents mean or average response of five repeated measurements).

The specimens are marked from 1 to 20 according to the standard run order, i.e. conventional schedule for CCD. It means the specimens numbered from 1 to 8 are the points of factorial design, the specimens numbered from 9 to 14 are the axial points and finally, the specimens numbered from 15 to 20 are the points at the center of design (6 replicates). It can be seen that the specimen number 8 (factorial point) was first machined and the specimen number 4 (also factorial point) was the last.

Statistical analysis of the measured response (given in Table III), as well as randomization, were conducted using the licensed software Design Expert (version DX8, 8.0.7.1, Stat-Ease, Inc. Minneapolis, 2010). The minimum value of the response is $0.52 \mu \mathrm{m}$ and the maximum value amounts to $7.11 \mu \mathrm{m}$. The mean is $5.1 \mu \mathrm{m}$, and the sample standard deviation is $2.04 \mu \mathrm{m}$ (i.e. sample variance is 4.18 ). The full quadratic regression model is obtained and the terms $A, A^{2}, A B$ and $A C$ are removed because they are not significant in the model. Therefore, Table IV presents the Analysis of variance for the reduced model. 
Table III: The results of the experiment.

\begin{tabular}{|c|c|c|c|c|c|}
\hline $\begin{array}{c}\text { Standard } \\
\text { Order or Mark } \\
\text { of specimen }\end{array}$ & Run & $\begin{array}{c}\text { Factor 1 } \\
A: \text { Depth of } \\
\text { cut }(\mathrm{mm})\end{array}$ & $\begin{array}{c}\text { Factor 2 } \\
\begin{array}{c}B: \text { Feed rate } \\
(\mathrm{mm} / \mathrm{min})\end{array}\end{array}$ & $\begin{array}{c}\text { Factor 3 } \\
C \text { Number of revolutions, } \\
(\mathrm{rev} / \mathrm{min})\end{array}$ & $\begin{array}{c}\text { Response- } \\
\text { Roughness } R_{a}, \\
(\mu \mathrm{m})\end{array}$ \\
\hline 8 & 1 & 0.80 & 100 & 1000 & 5.82 \\
\hline 20 & 2 & 0.55 & 75 & 750 & 5.21 \\
\hline 11 & 3 & 0.55 & 32.96 & 750 & 0.52 \\
\hline 9 & 4 & 0.13 & 75 & 750 & 5.86 \\
\hline 3 & 5 & 0.30 & 100 & 500 & 7.11 \\
\hline 13 & 6 & 0.55 & 75 & 329.55 & 6.11 \\
\hline 2 & 7 & 0.80 & 50 & 500 & 5.14 \\
\hline 6 & 8 & 0.80 & 50 & 1000 & 0.83 \\
\hline 12 & 9 & 0.55 & 117.04 & 750 & 6.97 \\
\hline 10 & 10 & 0.97 & 75 & 750 & 5.76 \\
\hline 18 & 11 & 0.55 & 75 & 750 & 5.85 \\
\hline 5 & 12 & 0.30 & 50 & 1000 & 1.15 \\
\hline 15 & 13 & 0.55 & 75 & 750 & 6.21 \\
\hline 1 & 14 & 0.30 & 50 & 500 & 6.25 \\
\hline 14 & 15 & 0.55 & 75 & 1170.45 & 2.75 \\
\hline 19 & 16 & 0.55 & 75 & 750 & 6.18 \\
\hline 7 & 17 & 0.30 & 100 & 1000 & 6.19 \\
\hline 17 & 18 & 0.55 & 75 & 750 & 5.81 \\
\hline 16 & 19 & 0.55 & 75 & 750 & 5.76 \\
\hline 4 & 20 & 0.80 & 100 & 500 & 6.70 \\
\hline
\end{tabular}

Table IV: Analysis of variance for the reduced model.

\begin{tabular}{|l|c|c|c|c|c|}
\hline \multicolumn{1}{|c|}{ Source } & $\begin{array}{c}\text { Sum of } \\
\text { Squares, } S S\end{array}$ & $d f$ & $\begin{array}{c}\text { Mean } \\
\text { Square, } M S\end{array}$ & $\begin{array}{c}F \\
\text { Value }\end{array}$ & $\begin{array}{c}p \text {-value } \\
\text { Prob }>F\end{array}$ \\
\hline Model & 76.605 & 5 & 15.321 & 76.457 & $<0.0001$ \\
\hline$B$-Feed rate & 39.713 & 1 & 39.713 & 198.185 & $<0.0001$ \\
\hline $\begin{array}{l}C \text {-Number of } \\
\text { revolutions }\end{array}$ & 20.841 & 1 & 20.841 & 104.005 & $<0.0001$ \\
\hline$B C$ & 7.258 & 1 & 7.258 & 36.220 & $<0.0001$ \\
\hline$B^{2}$ & 6.732 & 1 & 6.732 & 33.594 & $<0.0001$ \\
\hline$C^{2}$ & 2.768 & 1 & 2.768 & 13.816 & 0.0023 \\
\hline Residual & 2.805 & 14 & 0.200 & & \\
\hline Lack of Fit & 2.145 & 9 & 0.238 & 1.805 & 0.2671 \\
\hline Pure Error & 0.660 & 5 & 0.132 & & \\
\hline Cor Total & 79.410 & 19 & & & \\
\hline
\end{tabular}

The mean square for the regression is 15.321 and $F$ ratio amounts to 76.457 (15.321 divided by 0.2 ) which is higher than the critical $F$ ratio (2.96). Thus, the null hypothesis can be rejected and the alternative one can be accepted. It means that at least one of the regression variables contributes significantly to the model. The model terms $B, C, B C, B^{2}$ and $C^{2}$ are significant; $p$ values for the $F$ statistics $(198.185 ; 104.005 ; 36.220 ; 33.594$ and 13.816$)$ are much smaller than the probability of type I error 0.05 , i.e. the significance level. As previously mentioned, the terms $A, A B, A C$ and $A^{2}$ are not significant ( $p$ values for the $F$ statistics $(1.87 ; 0.24 ; 0.37$ and 0.20$)$ were higher than the probability of type I error 0.05$)$. It is not shown in Table IV; it is concluded from the analysis of variance for the full model. The testing of Lack of fit is also conducted. For our experiment, this value is not significant, because the $F$ statistic $(0.238 / 0.132=1.805)$ is smaller than the critical one of 4.77 . This is good. Finally, the addition of center points to our design allowed us to estimate pure error because of the replications. The coefficient of multiple determination $R^{2}$ amounts to 0.965 and 
presents the portion of explained variability in total variability; it is calculated from Eq. (1); $S S$ means Sum of Squares.

$$
R^{2}=\frac{S S_{\text {model }}}{S S_{\text {total }}}=1-\frac{S S_{\text {residual }}}{S S_{\text {total }}}
$$

Adjusted coefficient of determination $R^{2}$ adj is equal to 0.952 and we can use it because it is not dependent on the number of variables added to the regression model $\left(R_{\text {adj }}^{2}\right.$ is calculated from Eq. (2); $m$ is the number of runs and $r$ is the number of regression model terms).

$$
R_{\text {adj }}^{2}=1-\frac{S S_{\text {residual }} /(m-r)}{S S_{\text {total }} /(m-1)}=1-\left(\frac{m-1}{m-r}\right)\left(1-R^{2}\right)
$$

Since the ordinary and adjusted coefficients of determination do not differ significantly, we can conclude that probably nonsignificant terms are not included in the model. The coefficients of determination of the model obtained in this way are high (0.965 or 0.952 adjusted) which is very good, as well as the insignificant lack of fit. Therefore, the conclusion can be drawn that the regression model provides a very good fit and can be used to predict roughness throughout the region of experimentation. The prediction error sum of squares PRESS is 8.35 , and consequently $R^{2}$ for prediction in our experiment amounts to 0.89 . These two values are the measures of predicting the response in a new experiment [29].

The coefficient of variation C.V. \% is the portion of error (i.e. standard deviation) in the mean and is equal to $8.76 \%$. The reduced model in terms of coded factors is presented by Eq. (3) (see the coded scale of factors in Table II).

$$
R_{a}=5.87+1.71 \cdot B-1.24 \cdot C+0.95 \cdot B \cdot C-0.68 \cdot B^{2}-0.44 \cdot C^{2}
$$

The reduced model in terms of natural (actual) factors is presented by Eq. (4) (see the actual levels of factors in Table II).

$$
R_{a}=2.987+0.117 \cdot f-0.0059 \cdot n+0.00015 \cdot f \cdot n-0.0011 \cdot f^{2}-0.00000697 \cdot n^{2}
$$

Fig. 1 presents the response surface, where roughness is plotted versus the levels of feed rate and the number of revolutions, with a constant value of depth of cut $(0.55 \mathrm{~mm})$. It can be seen that with higher values of the number of revolutions and lower values of feed rate, the values of roughness are lower, i.e. better. Minimum roughness of $0.86 \mu \mathrm{m}$ is achieved at the high level of number of revolutions and at the low level of feed rate.

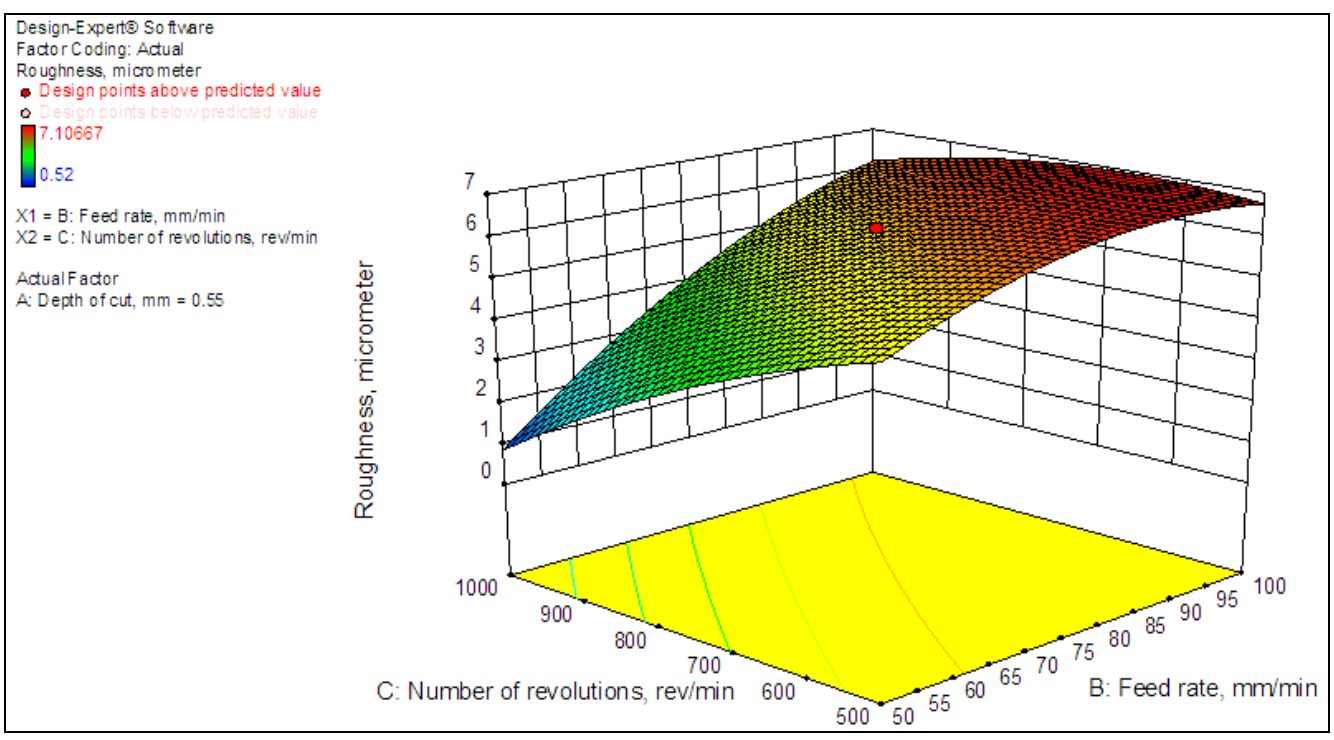

Figure 1: Response surface plot for the regression model. 
Model adequacy checking is also performed. Normality assumption (the residuals can be described by a normal distribution, that is, the residuals are normally and independently distributed random variables with the mean zero) is checked using the normal probability plot. From the visual examination of the normal probability plot (Fig. 2a) we can see that the cumulative frequency or probability of internally studentized residuals falls approximately along a straight line. There is only one moderate violation which does not affect the analysis of variance. Fig. $2 \mathrm{~b}$ shows the relationship between the predicted values calculated by the model (by using Eqs. (3) and (4)) and those obtained by the experiment (actual). It can be seen that those values correlate very well. The value of roughness at the center point calculated by the models in Eqs. (3) and (4) equals $5.87 \mu \mathrm{m}$, while the average experimental value of five runs at the center point (runs no. 2, 11, 13, 18 and 19; Table III) amounts to 5.84 $\mu \mathrm{m}$. There is no significant difference between the model and the experiment.

Finally, a confirmation run is carried out to test the regression model, that is, to predict new response observation at the point $x_{0}$. A confirmation run is performed with the following:

- factor $A$ - coded value of 1.68 or actual value of $0.97 \mathrm{~mm}$,

- factor $B$ - coded value of 1 or actual value of $100 \mathrm{~mm} / \mathrm{min}$,

- factor $C$ - coded value of -1 or actual value of $500 \mathrm{rev} / \mathrm{min}$.
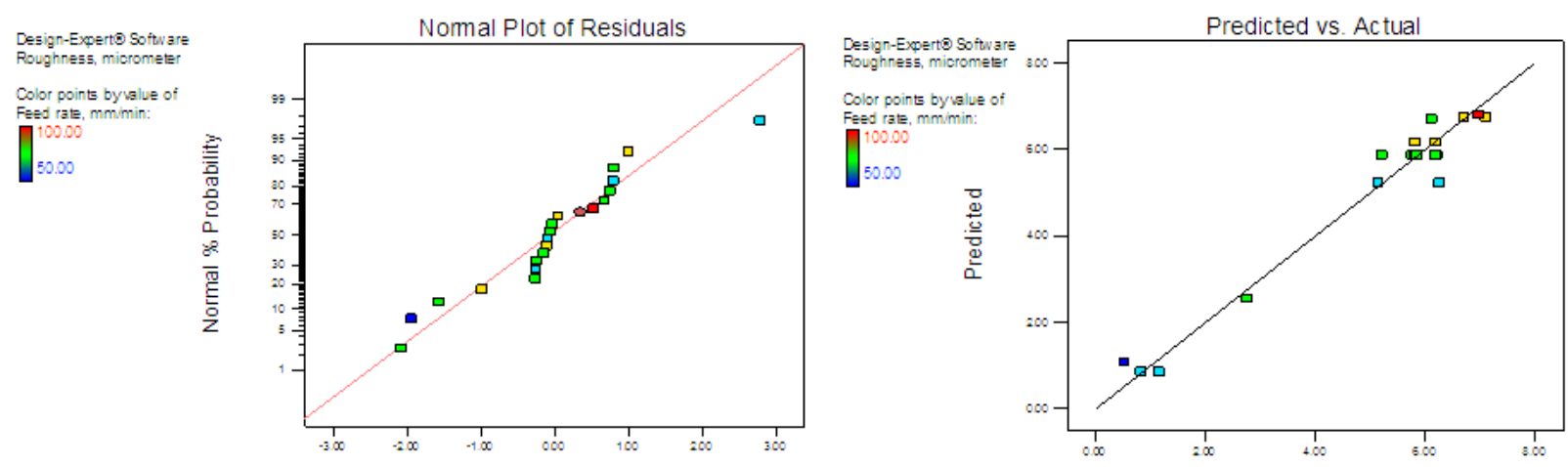

a)

Internally Studentized Residuals

b)

Actual

Figure 2: a) Normal probability plot of residuals;

b) Predicted response (roughness) related to the measured response.

The predicted value of the response at that point is $6.74 \mu \mathrm{m}-$ it is calculated from the regression model (Eqs. (3) or (4)). According to the Eq. (5) [29], a 100(1- $\alpha$ ) per cent prediction interval for a new observation $y_{0}$ can be calculated:

$$
\hat{y}\left(x_{0}\right)-t_{\alpha / 2, m-r} \sqrt{\hat{\sigma}^{2}\left(1+x_{0}^{\prime}\left(X^{\prime} X\right)^{-1} x_{0}\right)} \leq y_{0} \leq \hat{y}\left(x_{0}\right)+t_{\alpha / 2, m-r} \sqrt{\hat{\sigma}^{2}\left(1+x_{0}^{\prime}\left(X^{\prime} X\right)^{-1} x_{0}\right)}
$$

where:

$\hat{y}\left(x_{0}\right)$ - value of response predicted by the regression model at new observation point $x_{0}$,

$t_{\alpha / 2, m-r}-$ value of variable of $t$ distribution with $m-r$ degrees of freedom, for defined probability $\alpha$ of the type I error,

$m \quad-$ number of runs,

$r \quad$ - number of regression model terms,

$\hat{\sigma}^{2}-$ unbiased estimator of variance,

$X \quad$ matrix of the levels of the independent variables,

$X^{\prime} \quad-$ transpose of the matrix $X$.

The interval within which the new observation would be expected to lie is from 5.63 to 7.85 $\mu \mathrm{m}$. The actual average value of surface roughness in confirmation experiment was $6.85 \mu \mathrm{m}$. 


\section{NEURAL NETWORK BASED MODELLING}

The observed research belongs to the problems dealing with continuous input and output values i.e. problems connected with prediction, thus the back-propagation network is applied. During the process of learning the aim is to enable fast convergence and reduce global error given by Eq. (6).

$$
E=0,5 \cdot \sum\left(d_{k}-x_{k}\right)^{2}
$$

where $d_{k}$ is desired (real) output, while $x_{k}$ presents the output of the network and $k$ is the index of output component.

In this type of network global error propagates backwards through the network all the way to the input layer. During the backward pass all weighted connections are adjusted in accordance with the desired neural network output values. Increase or decrease of the actual values of the weights $w_{j i}^{[s]}$ affects the decrease of global error.

By the application of the gradient descent rules the increase in the network weighted connections $\Delta w_{j i}^{[s]}$ can be given as:

$$
\Delta w_{j i}^{[s]}=-\alpha \cdot\left(\frac{\partial E}{\partial w_{j i}^{[s]}}\right)
$$

where $\alpha$ is the learning coefficient.

Derivations given above can be calculated as:

$$
\frac{\partial E}{\partial w_{j i}^{[s]}}=\left(\frac{\partial E}{\partial I_{j}^{[s]}}\right) \cdot\left(\frac{\partial I_{j}^{[s]}}{\partial w_{j}^{[s]}}\right)=-e_{j}^{[s]} \cdot x_{j}^{[s-1]}
$$

where $I_{j}^{[s]}$ is weighted sum of input of the $j^{\text {th }}$ neuron in the $s^{\text {th }}$ layer.

The value of the weighted connections increase in the network $\Delta w_{j i}^{[s]}$ is now:

$$
\Delta w_{j i}^{[s]}=\alpha \cdot e_{j}^{[s]} \cdot x_{j}^{[s-1]}
$$

where $x_{j}^{[s]}$ represents output state of the $j^{\text {th }}$ neuron in the $s^{\text {th }}$ layer, and the parameter $e_{j}^{[s]}$ that represents the error and propagates backwards through all the layers of the network is defined as:

$$
e_{j}^{[s]}=\frac{-\partial E}{\partial I_{j}^{[s]}}
$$

The learning coefficient should be kept low to avoid divergence although this could result in very slow learning. This situation is solved by including a momentum term into Eq. (9):

$$
\Delta w_{j i}^{[s]}=\alpha \cdot e_{j}^{[s]} \cdot x_{j}^{[s-1]}+\text { momentum } \Delta w_{j i}^{[s]}
$$

The weights in the network can be updated for each learning vector separately or else cumulatively, which considerably speeds up the rate of learning (convergence).

Therefore the objective of the learning process in a neural network is to achieve the lowest possible level of error between the outputs obtained by training the network and the actual (desired) results. This is realized by adjusting the weights of the neurons, and by accepting the objective function, defined below through the minimization of the mean square error.

General form vector of the model applicable for a neural network input is as follows:

$$
X_{i}=\left\{x_{i 1}, x_{i 2}, x_{i 3}, \ldots, x_{i n}\right\} \Rightarrow Y_{o}=\left\{y_{o 1}, y_{o 2}, y_{o 3}, \ldots, y_{o n}\right\}
$$

where vector $X_{i}$ represents input variables, and vector $Y_{o}$ output variables. 
In the given problem the model vector has one output variable - the surface roughness. Input variables are: depth of cut, feed rate and number of revolutions (spindle speed), see Table V.

Table V: Variables with a value range for the proposed model.

\begin{tabular}{|c|l|c|c|}
\hline No. & Variable & Minimum value & Maximum value \\
\hline 1. & depth of cut & $0.13 \mathrm{~mm}$ & $0.97 \mathrm{~mm}$ \\
\hline 2. & feed rate & $32.96 \mathrm{~mm} / \mathrm{min}$ & $117.04 \mathrm{~mm} / \mathrm{min}$ \\
\hline 3. & number of revolutions (spindle speed) & $329.55 \mathrm{rev} / \mathrm{min}$ & $1170.45 \mathrm{rev} / \mathrm{min}$ \\
\hline
\end{tabular}

The RMS error (Root Mean Square error) is taken as a criterion for network validation. The Delta rule is applied for network training. This rule is also called the Widrow/Hoff rule or the minimum mean square rule which has become one of the basic rules in the training process of most neural networks.

In Eq. (13) the formula for the Delta rule is given:

$$
\Delta w_{j i}=\alpha \cdot y_{c j} \cdot \varepsilon_{i}
$$

where $y_{c j}$ is output value computed in neuron $j, \Delta w_{j i}$ is the value of the difference in the weights of neuron $j$ and neuron $i$ realized in two steps $\left(k^{\text {th }}\right.$ and $\left.k-1\right)$, mathematically described by Eq. (14):

$$
\Delta w_{j i}=\Delta w_{j i}^{k}-\Delta w_{j i}^{k-1}
$$

$y_{c j}$ is the output value of neuron $j$ calculated according to transfer function, $\varepsilon_{i}$ is the error given as:

$$
\varepsilon_{i}=y_{c i}-y_{d i}
$$

where $y_{d i}$ is the actual (desired) output. The error given by the expression (15) returns to the network only rarely, other forms of error are used instead depending on the kind of network.

For most actual problems various rates of learning are used for various layers with a low rate of learning for the output layer. It is usual for the rate of learning to be set at a value anywhere in the interval between 0.05 and 0.5 , the value decreasing during the learning process. While using the Delta rule algorithm the used data are to be selected from the training set at a random basis. Otherwise frequent oscillations and errors in the convergence of results can be expected.

The transfer function used in this study is the Sigmoid function calculated according to Eq. (16).

$$
\text { Output }_{i}=\frac{1}{1+e^{-G \text { :input }}}
$$

where $G$ is the function increment. It is calculated as $G=1 / T . T$ is the function threshold. This function is often used when neural networks are created or investigated. The function graph is continuously monotonous. The values of this transmission function are in the interval [0,1].

The study of the application of the back-propagation network was carried out for a defined data model. By alternating the attributes diverse architectures of neural networks were studied. The network with the best architecture generated the network output with $3.41 \%$ rate of $R M S$ error in the training phase and $4.01 \%$ in the validation phase. The graph in Fig. 3 shows the results obtained by this network structure with regard to experimental results. In Fig. 3a the roughness obtained by the NN model is compared with experimental values from the set designed for neural network training and in Fig. $3 \mathrm{~b}$ with experimental values from the set designed for validation. 

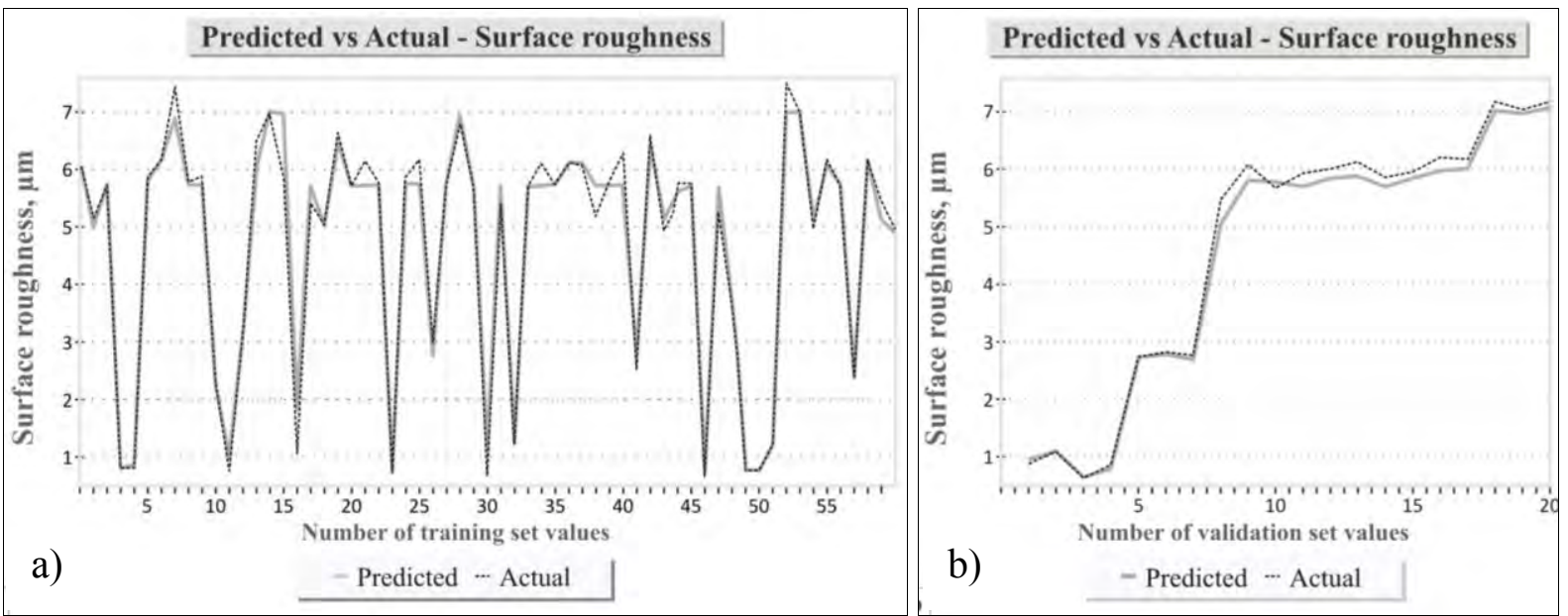

Figure 3: Presentation of actual values and predicted values given by $\mathrm{NN}$ for the surface roughness; a) training set; b) validation set.

The graphs give evidence of good prediction of roughness by the neural networks model, the correlation coefficient being 0.991 .

Fig. 4 shows the relationship between the predicted values calculated by the NN model and those obtained by the experiment (actual). It can be seen that those values correlate very well.

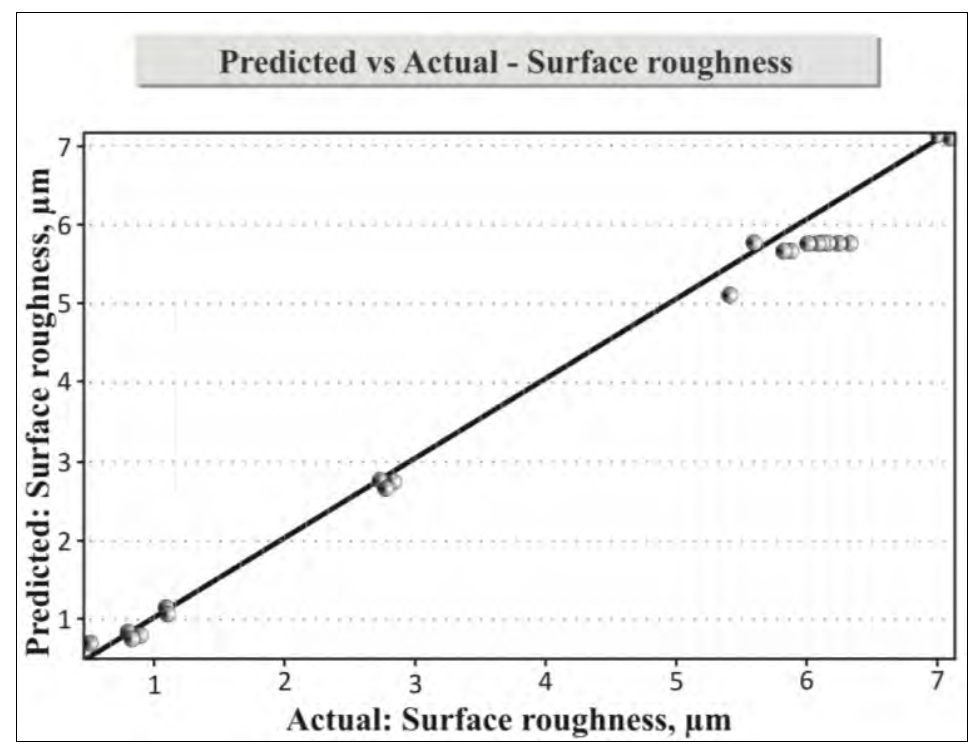

Figure 4: Predicted (by NN model) response (roughness) related to the measured response.

\section{COMPARISON AND VERIFICATION OF THE MODELS}

Fig. 5 displays the ranges of the roughness experimental values for all of 20 samples. Some of the ranges are markedly narrow indicating material homogeneity and in the course of time equalized features that characterize cutting, tool, machine, roughness evaluation device and environment. The figure emphasizes roughness values predicted by the regression and NN model. Good agreement can be seen with experimental results within the range of cutting parameters applied in the experiment. The error is within the limit of $5 \%$, acceptable in practice. 


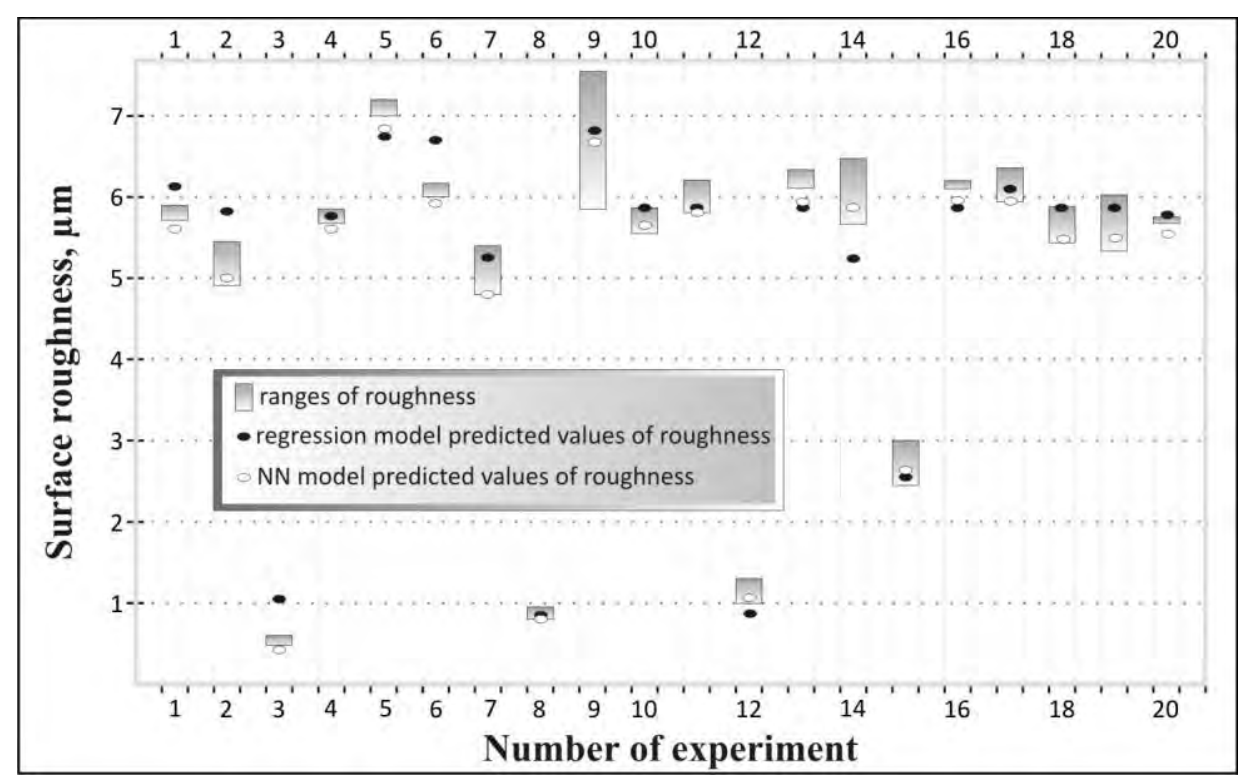

Figure 5: Ranges of roughness and the regression and NN model predicted values of roughness.

\section{CONCLUSIONS}

Surface roughness, defined by a number of controlled and uncontrolled parameters, often serves as an important indicator or measure of surface quality and exerts essential influence on technological time and total productivity, therefore on production costs too. The aim of the investigation, presented in this paper, was to model the surface roughness in end milling of aluminium alloy on a low power cutting machine, based on planned experimentation. Investigations on such machines are not frequently and commonly carried out.

A quadratic regression model is fitted to the experimental data with a very satisfactory coefficient of determination (0.965). The method of least squares is used to estimate the regression coefficients. The above mentioned regression model can be used to calculate and predict well the surface roughness within the chosen and determined range of input variables. The NN model approximates well the experimental results with the level of RMS error (Root Mean Square error) of $4.01 \%$ in the validation phase with the correlation coefficient of 0.991 . Therefore, both models are applicable but the adoption of other parameters (cutting conditions, tool geometry, tool machine vibrations, tool wear etc.) would increase the complexity and level of their applicability.

Further investigation will combine the fuzzy logic and neural networks with the new parameter (cooling condition) included.

\section{REFERENCES}

[1] Stankovic, I.; Perinic, M.; Jurkovic, Z.; Mandic, V.; Maricic, S. (2012). Usage of Neural Network for the Prediction of Surface Roughness after the Roller Burnishing, Metalurgija, Vol. 51, No. 2, 207-210

[2] Vukelic, D.; Tadic, B.; Miljanic, D.; Budak, I.; Todorovic, P. M.; Randjelovic, S.; Jeremic, B. M. (2012). Novel Workpiece Clamping Method for Increased Machining Performance, Tehnicki vjesnik - Technical Gazette, Vol. 19, No. 4, 837-846

[3] Antic, A.; Petrovic, P. B.; Zeljkovic, M.; Kosec, B.; Hodolic, J. (2012). The Influence of Tool Wear on the Chip-Forming Mechanism and Tool Vibrations, Materiali in tehnologije, Vol. 46, No. 3, 279-285 
[4] Tadic, B.; Jeremic, B.; Todorovic, P.; Vukelic, D.; Proso, U.; Mandic, V.; Budak, I. (2012). Efficient Workpiece Clamping by Indenting Cone-shaped Elements, International Journal of Precision Engineering and Manufacturing, Vol. 13, No. 10, 1725-1735, doi:10.1007/s12541-012$0227-8$

[5] Stampfer, M. (2009). Automated setup and fixture planning system for box-shaped parts, International Journal of Advanced Manufacturing Technology, Vol. 45, No. 5-6, 540-552, doi:10.1007/s00170-009-1983-1

[6] Cardoso, P.; Davim, J. P. (2012). Micro milling of metallic materials - a brief overview, Transactions of FAMENA, Vol. 36, No. 2, 79-85

[7] Rajmohan, T.; Palanikumar, K. (2011). ANN model to predict surface roughness in drilling hybrid composites, Advances in Production Engineering \& Management, Vol. 6, No. 4, 281-290

[8] Cosic, P.; Lisjak, D.; Antolic, D. (2011). Regression Analysis and Neural Networks as Methods for Production Time Estimation, Tehnicki vjesnik - Technical Gazette, Vol. 18, No. 4, 479-484

[9] Tamizharasan, T.; Senthil Kumar, N. (2012). Optimization of cutting insert geometry using deform-3D numerical simulation and experimental validation, International Journal of Simulation Modelling, Vol. 11, No. 2, 65-76. doi:10.2507/IJSIMM11(2)1.200

[10] Zain, A. M.; Haron, H.; Qasem, S. N.; Sharif, S. (2012). Regression and ANN models for estimating minimum value of machining performance, Applied Mathematical Modelling, Vol. 36, No. 4, 1477-1492, doi:10.1016/j.apm.2011.09.035

[11] Bajic, D.; Celent, L.; Jozic, S. (2012). Modeling of the influence of cutting parameters on the surface roughness, tool wear and cutting force in face milling in off-line process control, Strojniski vestnik - Journal of Mechanical Engineering, Vol. 58, No. 11, 673-682, doi:10.5545/sv-jme.2012.456

[12] Munoz-Escalona, P.; Maropoulos, P. G. (2010). Artificial Neural Networks for Surface Roughness Prediction when Face Milling Al 7075-T7351, Journal of Materials Engineering and Performance, Vol. 19, No. 2, 185-193, doi:10.1007/s11665-009-9452-4

[13] Öktem, H. (2009). An integrated study of surface roughness for modelling and optimization of cutting parameters during end milling operation, International Journal of Advanced Manufacturing Technology, Vol. 43, No. 9-10, 852-861, doi:10.1007/s00170-008-1763-3

[14] Raju, K. V. M. K.; Janardhana, G. R.; Kumar, P. N.; Rao, V. D. P. (2011). Optimization of cutting conditions for surface roughness in CNC end milling, International Journal of Precision Engineering and Manufacturing, Vol. 12, No. 3, 383-391, doi:10.1007/s12541-011-0050-7

[15] Samanta, B. (2009). Surface roughness prediction in machining using soft computing, International Journal of Computer Integrated Manufacturing, Vol. 22, No. 3, 257-266, doi:10.1080/09511920802287138

[16] Samanta, B.; Erevelles, W.; Omurtag, Y. (2008). Prediction of workpiece surface roughness using soft computing, Proceedings of the Institution of Mechanical Engineers Part B - Journal of Engineering Manufacture, Vol. 222, No. 10, 1221-1232, doi:10.1243/09544054JEM1035

[17] Lela, B.; Bajic, D.; Jozic, S. (2009). Regression analysis, support vector machines, and Bayesian neural network approaches to modeling surface roughness in face milling, International Journal of Advanced Manufacturing Technology, Vol. 42, No. 11-12, 1082-1088, doi:10.1007/s00170$008-1678-\mathrm{Z}$

[18] Kumanan, S.; Jesuthanam, C. P.; Kumar, R. A. (2008). Application of multiple regression and adaptive neuro fuzzy inference system for the prediction of surface roughness, International Journal of Advanced Manufacturing Technology, Vol. 35, No. 7-8, 778-788, doi:10.1007/s00170006-0755-4

[19] Zhang, J. Z.; Chen, J. C. (2007). The development of an in-process surface roughness adaptive control system in end milling operations, International Journal of Advanced Manufacturing Technology, Vol. 31, No. 9-10, 877-887, doi:10.1007/s00170-005-0262-z

[20] Petropoulos, G.; Pandazaras, C.; Stamos, I. (2003). Study of the main variability aspects of surface texture of steel in face milling, Proceedings of the Institution of Mechanical Engineers Part J - Journal of Engineering Tribology, Vol. 217, No. 2, 175-180, doi:10.1243/ $\underline{13506500360603606}$ 
[21] Barber, G. C.; Gu, R.; Jiang, Q.; Gu, J.; Tung, S. (2001). Surface roughness model for worn inserts of face milling: Part II - An empirical model, Tribology Transactions, Vol. 44, No. 1, 142146, doi:10.1080/10402000108982438

[22] Wibowo, A.; Desa, M. I. (2012). Kernel based regression and genetic algorithms for estimating cutting conditions of surface roughness in end milling machining process, Expert Systems with Applications, Vol. 39, No. 14, 11634-11641, doi:10.1016/j.eswa.2012.04.004

[23] El-Sonbaty, I. A.; Khashaba, U. A.; Selmy, A. I.; Ali, A. I. (2008). Prediction of surface roughness profiles for milled surfaces using an artificial neural network and fractal geometry approach, Journal of Materials Processing Technology, Vol. 200, No. 1-3, 271-278, doi:10.1016/ j.jmatprotec.2007.09.006

[24] Zain, A. M.; Haron, H.; Sharif, S. (2010). Prediction of surface roughness in the end milling machining using artificial neural network, Expert Systems with Applications, Vol. 37, No. 2, 1755-1768, doi:10.1016/j.eswa.2009.07.033

[25] Razfar, M. R.; Zinati, R. F.; Haghshenas, M. (2011). Optimum surface roughness prediction in face milling by using neural network and harmony search algorithm, International Journal of Advanced Manufacturing Technology, Vol. 52, No. 5-8, 487-495, doi:10.1007/s00170-010-2757-5

[26] Palani, S.; Natarajan, U. (2011). Prediction of surface roughness in CNC end milling by machine vision system using artificial neural network based on 2D Fourier transform, International Journal of Advanced Manufacturing Technology, Vol. 54, No. 9-12, 1033-1042, doi:10.1007/ $\underline{\mathrm{s} 00170-010-3018-3}$

[27] Harih, G.; Dolsak, B. (2013). Tool-handle design based on a digital human hand model, International Journal of Industrial Ergonomics, Vol. 43, No. 4, 288-295, doi:10.1016/ j.ergon.2013.05.002

[28] Bruni, C.; d'Apolito, L.; Forcellese, A.; Gabrielli, F.; Simoncini, M. (2008). Surface roughness modelling in finish face milling under MQL and dry cutting conditions, International Journal of Material Forming, Vol. 1, No. 1 supplement, 503-506, doi:10.1007/s12289-008-0151-8

[29] Montgomery, D. C. (2009). Design and Analysis of Experiment, John Wiley and Sons, Inc., Hoboken 